\title{
Role of UVA1 phototherapy in treatment of scleroderma and scleroderma-like disorders
}

\author{
AGNIESZKA OSMOLA-MAŃKOWSKA, ALEKSANDRA DAŃCZAK-PAZDROWSKA, \\ KAROLINA OLEK-HRAB, WOJCIECH SILNY
}

Chair and Department of Dermatology, Poznan University of Medical Sciences, Poznań, Poland

\begin{abstract}
Treatment of scleroderma and scleroderma-like diseases poses a serious challenge to contemporary dermatology due to the complexity of its pathogenesis, low incidence of the diseases and their heterogenous clinical expression. the manifestation of this autoimmune disease includes an increased production and deposition of collagen fibres types I and III in the skin and connective tissue as well as vascular alterations. Ultraviolet A1 (UVA1) phototherapy affects various stages of a morbid process in scleroderma: it inhibits inflammation and affects the consequences of it, fibrosis. Currently, UVA1 is proposed as a potential treatment and is believed to have a multifold mechanism of action. This includes, inducing apoptosis in $T$ and $B$ lymphocytes, inhibition of proinflammatory cytokine production and ability to induce collagenase production by fibroblasts. UVA1 irradiation may also interact with endothelial cells, promoting angiogenesis. Efficacy of high, moderate, and low doses of UVA1 was documented. Advantages of UVA1 phototherapy include the evident avoidance of systemic side effects of psoralens such as nausea and vomiting or photokeratitis as well as lower risk of phototoxic reactions with deeper penetration of radiation. Its disadvantages include high cost of equipment, thus reducing the accessibility of the treatment to specialized centres. Due to its unique mechanism of action, attempts to use UVA1 phototherapy seem justified in other rare diseases, developing with skin induration.
\end{abstract}

Key words: phototherapy, UVA1, treatment, scleroderma, morphea, lichen sclerosus, scleredema, scleromyxedema, graft-versus-host disease.

(Centr Eur J Immunol 2012; 37 (4): 391-398)

\section{Introduction}

Treatment of scleroderma and scleroderma-like diseases poses a serious challenge to contemporary dermatology due to the complexity and of its pathogenesis, low incidence of the disease and its heterogenous clinical expression. Recent treatment regimes, which include immunosuppressant drugs, produce many undesirable effects. Introduction of photochemotherapy (psoralen + ultraviolet A - PUVA) followed by ultraviolet A1 (UVA1) phototherapy (which affects the fibrotic process) significantly enriched the therapeutic panel. In Poland, however, application of phototherapy in the indications remains still insufficiently widespread [1,2].

Lamps which emit narrow range, long wave UVA-1 radiation of 340-400 $\mathrm{nm}$ were produced in 1981 by Mutzhas et al. In 1992 Krutmann et al. published positive results of treatment of atopic dermatitis (AD) using high doses of UVA1 [3, 4]. At present, AD represents a standard indication for such therapy, formulated in modern consensus recommendations [5-7]. The other group of diseases in which UVA1 may be of therapeutic importance are fibrotic diseases such as generalised morphea.

Treatment of various connective tissue diseases took advantage mainly of wide range UVA (broad band UVA BB UVA), PUVA photochemotherapy, and UVA1. Ultraviolet $\mathrm{A} 1$ offers deeper penetration compared to that obtained with UVB as well as targeting fibrosis and other structures, i.e. fibroblasts, T-lymphocytes, Langerhans cells, mast cells, endothelial cells. Broad band UVA and PUVA radiation (range of 315 to $400 \mathrm{~nm}$, max. $340-360 \mathrm{~nm}$ ) reach-

Correspondence: Agnieszka Osmola-Mańkowska, Chair and Department of Dermatology, Poznan University of Medical Sciences, 49 Przybyszewskiego Street, 60-355 Poznań, Poland, phone +48 6186912 85, fax +48 61869 15 72, e-mail: agnieszka.osmola@wp.pl 
es papillary layer of dermis while UVA1 (range of 350 to $400 \mathrm{~nm}$, max. 365-375 nm) acts deeper in the dermis and even in the subcutaneous tissue. Moreover, around $20 \%$ of the radiation reaches vascular system which, according to some authors, provides grounds for a potential systemic action of this radiation range [8].

\section{Pathogenesis of scleroderma}

Manifestation of this autoimmune disease includes an increased production and deposition of collagen fibres types I and III in the skin and connective tissue as well as vascular alterations and an autoimmune process. The more localised form of the disease (morphea) differs from systemic one in such a way that it does not involve inner organs. However, the skin lesions in both are histologically identical. As a chronic disease, morphea does not affect longevity of patients but it definitely affects quality of patient's life. Depending on its form, orthopedic, neurologic and ophthalmologic complications may arise [9-11].

The pathogenesis of morphea remains unclear. Its clinical presentation involves an excessive fibrosis due to a disturbed turnover of the extracellular matrix. However, vascular lesions and immune system activation, including autoaggressive processes are developed prior to clinical evidence [12-16]. Although the initiation of the process remains unknown, possible risk factors include a specific, genetic background and various types of environmental factors (e.g. infectious factors, Borrelia burgdorferi, physical factors, e.g., trauma, radiotherapy, chemical factors, e.g., bleomycin, silica [15, 17-22]. Currently, it is suggested that the first stage of the disease involves injury of endothelial cells. This ultimately leads to their apoptosis and a lowered vascular density, which are associated with an infiltrate of inflammatory cells [12, 13, 23, 24]. The phenomena are accompanied by elevated serum concentration of adhesion molecules, including selectins $E$ and $P$, vascular cell adhesion molecule (VCAM)-1, and intercellular adhesion molecule (ICAM)-1 [25-27]. The stimulated endothelial cells, cells of inflammatory infiltrate, and finally activated fibroblasts provide the source of several cytokines and growth factors which may participate in pathogenesis of the disease. This include profibrotic factors [transforming growth factor $\beta$ - TGF- $\beta$, connective tissue growth factor (CTGF), interleukin 4 (IL-4), IL-13], angiogenic factors [IL-8, vascular endothelial growth factor (VEGF)], and proinflammatory factors [IL-1, tumor necrosis factor $\alpha$ (TNF- $\alpha)$ ] [27-29]. In parallel, a lowered production is postulated of cytokines manifesting antifibrotic properties, such as interferon $\gamma($ INF- $\gamma)$ [30, 31]. However, attempts to introduce the latter to morphea treatment did not show favourable results. Additionally, soma cases of induced type SSc in multiple sclerosis patients treated with INF- $\gamma$ were found $[28,31]$. Moreover, intensified deposition of extracellular matrix components, including collagen I and III, fibronectin, gly- cosaminoglycans depends on their intensified production and, on diminished decomposition by matrix metalloproteinases [14, 32-35].

Recognition of individual stages of the complex pathogenesis is indispensable for any search aimed at detecting potential targets for new therapeutic approaches. Despite numerous investigations, the therapeutic potential still remains restricted. The currently accepted therapy focuses on controlling individual pathogenetic phases, i.e. the inflammatory, vascular, or fibrotic phase, using glucosteroids, penicillamine, derivatives of vitamin D, tacrolymus, methotrexate and other drugs. In more severe cases, however, linked approaches provide better results, e.g., association of glucocorticoid anti-inflammatory action with methotrexate-induced immunomodulation [9-11].

\section{Phototherapy in morphea}

In 1994, Kerscher et al. applied photochemotherapy for the first time using PUVA bath in two patients with morphea, employing 20 exposures 4 times per week for 6-8 weeks followed by 10 exposures twice a week, which resulted in both clinical and histological improvement [36]. One year later the same author treated 10 patients applying UVA1 phototherapy with a low dose of $20 \mathrm{~J} / \mathrm{cm} 24$ times a week for 6 weeks, and noting improvement after 15 exposures and a significant improvement following 24 exposures in over 80\% foci of morphea [37]. In 1998 Kerscher et al. again reported a good effect of treatment in 30 patients administered with a low dose of UVA1 $\left(20 \mathrm{~J} / \mathrm{cm}^{2}\right.$ for 12 weeks with 30 exposures to the total dose of $600 \mathrm{~J} / \mathrm{cm}^{2}$ ) [38]. Egyptian investigators, El Mofty et al. in 2000 examined application of low, wide spectrum UVA doses (applicable in a PUVA chamber) in 12 patients with 20 exposures and obtained a good effect [39]. In 2004, the same authors compared various doses of wide spectrum UVA (5-10-20 $\mathrm{J} / \mathrm{cm}^{2}$ ) in consecutive 16-21-26 patients who received 20 exposures and detected better response in treatment of fresh foci [41] Stege et al. in 1997 conducted comparative studies on 10 patients with morphea, treated with a high UVA1 dose of $130 \mathrm{~J} / \mathrm{cm}^{2}$ and receiving 30 exposures to the total dose of $3900 \mathrm{~J} / \mathrm{cm}^{2}$ vs. 7 patients treated with a low dose of $20 \mathrm{~J} / \mathrm{cm}^{2}$ and receiving 30 exposures (total dose of $600 \mathrm{~J} / \mathrm{cm}^{2}$ ), demonstrating better results at higher dosages, compared to the lower dose [42]. At the end of 2006 the most valuable comparative study was published. A randomized study including 64 patients in three groups, treated consecutively with a low UVA1 dose, a moderate dose of UVA1 and a narrow band of UVB. The study demonstrated superiority of UVA1 over UVAB doses in clinical, histologic and high frequency ultrasonographic (HF USG) appraisal [42]. Subsequently, a few reports were published which confirmed usefulness of moderate UVA1 doses [43, 44]. In 2009, Anders et al. compared also a very significant retrospective study on 17 patients treated with mod- 
erate doses of UVA1 in the period between 6 month and 3 years earlier which demonstrated positive short- and longterm effects in clinical, HF USG, elastometric appraisals as well as comparing levels of collagen and its metabolites in serum and urine before and after the treatment [45].

In 2011, the paper of Pereira et al. appeared, dealing with evaluation of efficacy in treatment using low doses of UVA1 (the mean of $31 \mathrm{~J} / \mathrm{cm}^{2}$, on the average 33 exposures, the mean total dose of $1662 \mathrm{~J} / \mathrm{cm}^{2}$ ) in patients with various forms of scleroderma. The study included 21 patients: 11 patients with plaque-type morphea, 3 patients with linear morphea, 2 patients with generalized morphea, one patient with deep morphea, one 10-year old patient with pansclerotic morphea of children, and 3 patients with systemic sclerosis. The best clinical effect was obtained in the group of patients with plaque-type morphea, followed by patients with linear and systemic disease. A moderate effect was obtained in generalized morphea, poor effect in pansclerotic morphea while no response to treatment was seen in its deep form [46].

Pansclerotic morphea of children represents the only exception, in which according to recommendations UVA1 phototherapy can be applied in children below 18 years of life. In 1997, Gruss et al. reported positive effect of treatment with low UVA1 doses of $20 \mathrm{~J} / \mathrm{cm}^{2}, 4$ times a week for 8 weeks, including 32 exposures to the total dose of $640 \mathrm{~J} / \mathrm{cm}^{2}$ [47]. In the opinion of some authors, specific forms of scleroderma (i.e. deep scleroderma, en coup de sabre, and eosinophilic fasciitis) require systemic therapy due to the depth of developing process [48]. Literature on the subject contains description of a 44-year-old female with eosinophilic fascitis accompanied by a toxic liver injury due to cyclophosphamide treatment, treated with a moderate dose of UVA1 $\left(60 \mathrm{~J} / \mathrm{cm}^{2}, 31\right.$ exposures, $3 \times$ a week, linked to low $5 \mathrm{mg}$ doses of prednisone). A good tolerance of the treatment and improvement in HF USG and elastometry was demonstrated [49].

\section{Systemic sclerosis}

In 2000, Morita et al. irradiated skin lesions within forearms of 5 patients with systemic sclerosis (SSc), using a moderate UVA1 dose of $60 \mathrm{~J} / \mathrm{cm}^{2}, 30$ exposures. They achieved an improvement on skin temperature, elasticity, histological skin patterns, as well as an increased passive mobility in joints [50].

In 2000, subsequent authors, von Kobyletzki et al. treated the hands of 8 patients with low doses of UVA1 of $30 \mathrm{~J} / \mathrm{cm}^{2}$ 4 times a week for a total of 50 exposures. Seven out of 8 patients showed a significantly improved mobility and healing of ulcerations [51]. In 2004, Kreuter et al. irradiated a group of 18 patients with acrosclerosis using low dose of UVA1. They achieved improvement in 16 out of 18 patients as well as increased activity of collagenase and absence of relapses in a six month observation [52]. Recently, in a letter to editors a case description was published related to an excel- lent effect of a whole body irradiation using a moderate dose of UVA1 up to the total dose of $2225 \mathrm{~J} / \mathrm{cm}^{2}$ in a female patient with systemic sclerosis on microstomia type lesions [53].

\section{Mechanism of UVA action in skin lesions of scleroderma}

Ultraviolet A1 phototherapy is a method affecting various stages of the sclerodermal process. The therapy inhibits the inflammatory process, thus preventing the progression of the disease as well as altering fibrosis, an effect of the disease. The currently accepted mechanism incorporates several aspects, including:

1) immunomodulating activity by inducing apoptosis,

2) effect on production of proinflammatory cytokines,

3) ability to induce production of collagenase by fibroblasts,

4) interacting with endothelial cells, promoting angiogenesis.

Apoptosis occurs in T and B lymphocytes, as well as in immature proliferating mast cells. Krutmann and Morita suggested that induction of apoptosis in T lymphocytes under the effect of UVA1 represents the mechanism of action manifested by the treatment in AZS. A particular propensity for apoptosis is manifested by lymphoma T cells, which has found application in treatment of cutaneous T-cell lymphoma (CTCL), in which UVA1 may be equally or even more effective than PUVA [54]. In early stages of morphea apoptosis involves mainly $\mathrm{T}$ and $\mathrm{B}$ lymphocyte infiltrate. In later stages it may affect also fibroblasts, which has been demonstrated in in vitro tests [55]. Moreover, two mechanisms of the early and late apoptosis, respectively, have been distinguished. In early apoptosis, UVA induces active oxygen molecules (ROS), exerting indirect action on cell DNA which is not seen after PUVA treatment. According to Morita et al., the singlet oxygen induces expression of Fas/Fas ligand molecules at the surface of lymphocytes $\mathrm{T}$. Studies on Jurkat cells demonstrated that singlet oxygen affects mitochondria, opening cyclosporine A (CyA) CyAsensitive megachannels, which results in a decreased membrane potential of the cell and release of AIF, the apoptosisinitiating factor. Superoxide anions injure the mitochondrial megachannels while release of cytochrome $\mathrm{C}$ leads to CyAindependent apoptosis [48].

In contrast to UVB, UVA1 does not increase levels of serum IL-10 but it decreases concentration of proinflammatory cytokines, i.e. IL-12, responsible for antibodydependent cytotoxicity, activation of $\mathrm{T}$ lymphocytes and eosinophils. It induces IL-1 which, in turn, influences production of IL-6, increasing the level of collagenase production by fibroblasts.

The ability to increase production of collagenase by fibroblasts was originally demonstrated in in vitro studies. In fibroblast cultures exposed to UVA1, an increase in collagenase production took place (expression of collagenase I mRNA) in a dose-dependent manner [56]. Subsequent 
studies in in vivo skin biopsies containing morphea lesions after a cycle of irradiation with a high dose of UVA1 demonstrated a twenty-fold increase in expression of collagenase I mRNA [57].

UVA decreases activity of prolyl hydroxylase, responsible for stabilization of the collagen triple helix, it may also inhibit formation of cross-links within collagen fibres (55).

Ultraviolet A decreases expression of collagen I, collagen III and TGF- $\beta$ genes (COLI, COLIII, TGFB) and increases expression of matrix metaloproteinases (MMP) and IFN- $\gamma$. Decreased production of collagen involves not only collagen type I but, as shown in earlier studies, also collagen type III [58].

Effect of endothelial cells was studied in skin biopsies taken from 4 patients with morphea before and after a cycle of exposures to UVA1 using a low dose of $30 \mathrm{~J} / \mathrm{cm}^{2}, 4$ times a week for 8 weeks and, then, 3 times a week for 6 weeks up to the total dose of $1500 \mathrm{~J} / \mathrm{cm}^{2}$. In immunohistochemical experiments on angiostatic, angiogenic, and angioapoptotic factors; UVA1 was demonstrated to induce angiogenesis and to decrease apoptosis in endothelial cells [59].

\section{Scleroderma-like diseases}

Due to the above mechanism of action UVA1 phototherapy may be utilised in other rare diseases progressing with induration, linked to an immunological background, such as lichen sclerosus, chronic sclerodermoid graft versus host disease (cGvHD) and other like scleromyxoedema, scleroedema Buschke, POEMS syndrome (polyneuropathy, organomegaly, endocrinopathy, monoclonal protein, skin changes) or nephrogenic fibrosing dermopathy (NFD).

Lichen sclerosus is uncommon, sclerosing inflammatory dermatosis of unclear etiology which affects skin and genital mucous membranes. In some cases whitish papular lesions may overlap sclerotic plaques typically seen in morphea. Originally, efficacy of phototherapy was noted in cases of overlapping morphea and lichen sclerosus lesions. Subsequently, PUVA baths and low doses of UVA1 were applied in cases of non-sexual form of lichen sclerosus, resistant to externally applied steroids and/or calcineurin inhibitors. In two patients with lichen sclerosus treated with low doses of UVA1, Kreuter et al. observed regression of skin lesions within 10 months and an evident improvement in HF USG patterns [62]. The same authors subsequently described 10 patients treated with low doses of UVA1, $20 \mathrm{~J} / \mathrm{cm}^{2}, 4$ times a week for 10 weeks. Evident clinical improvement took place, confirmed by HF USG patterns, and one-year observation demonstrated relapse of lesions in only two patients [63]. Literature of the subject contains also descriptions of PUVA applied topically with a cream and applications of UVA1 in lichen sclerosus in the genital regions. In such cases, however, great caution is recommended due to an increased risk of squamocellular cancer development [64].
Graft-versus-host disease (GvHD) represents an autoimmune disease and its advancement ranges from local lesions to erythroderma with development of blisters, like in the toxic epidermal necrolysis. It is caused by immunocompetent lymphocytes from the grafted tissue that are capable of proliferation and attacking the host organs, such as the skin, liver and intestines. The chronic GvHD (cGvHD) which developes after 100 days most frequently occurs as a transition from acute GvHD but it may develop independently of the acute form. Skin and mucous membranes are involved in over $90 \%$ of cases and the skin may be one of the first organs involved. The skin lesions observed in cGvHD may resemble those seen in the course of lichen planus (the lichenoid form) or those in the course of scleroderma (the sclerodermoid form of GvHD). The latter form may lead to restricted mobility of joints and development of ulcerations. In prophylaxis and treatment of GvHD immunosuppressive drugs are employed, such as cyclosporin, glucocorticoids, tacrolymus, mofetil mycophenolate [65]. Unfortunately, their side effects include risk of infections and secondary tumours. Therefore, alternative methods of treatment are recommended, such as those employing immunomodulatory effects of ultraviolet radiation. To a certain extent, they may allow reduction in applied doses of immunosuppressants or even their substitution. Various methods of phototherapy were employed in treatment of acute and chronic GvHD, including extracorporal photopheresis (ECP), PUVA with oral administration of psoralen, PUVA baths, UVA1 and UVB. Similarity of the lesions to lichen planus provided rationale for application of PUVA photochemotherapy in treatment of the lichenoid form. Literature on the subject contains reports on efficacy of the method applied in parallel with an immunosuppressant treatment. However, efficacy of PUVA in treatment of the sclerodermoid form is not so evident. PUVA is suggested to be more effective in decreasing skin thickness while improvement in joint mobility used to be obtained employing UVA1 [66]. Literature on the subject contains few reports on application of UVA1 in treatment of cGvHD. Some of them demonstrated a significant improvement in reduction of dermatogenic contractures, partial remission of the lesions but some of the authors failed to obtain the therapeutic effect [67-74]. Unfortunately, an objective appraisal of efficacy in phototherapy remains practically impossible due to a frequent need to link it to immunosuppression and absence of generally accepted forms of grading the skin lesions. As compared to photochemotherapy, advantages of UVA1 therapy include: no need to apply psoralen and lower risk of phototoxic reactions, particularly in patients with hepatic involvement in the course of GvHD. However, due to the possible distant complications in the diseases, i.e. CTCL or GvHD, the ratio of advantages to risk should always be considered and, therefore, parallel treatment with CyA should be avoided [75]. In our centre a 44-year-old male lymphoma patient developed chronic sclerodermoid 
and, then, lichenoid form of GvHD after receiving a bone marrow graft from his sister. Originally, scleroderma-like lesions dominated and resulted in a restricted mobility in joints and the patient was treated with CyA. PUVA applied in 2009 brought a negligible effect. In 2009 the patient was exposed to the first cycle of UVA1 exposures, at $40 \mathrm{~J} / \mathrm{cm}^{2}$, 30 exposures up to the total dose of $1070 \mathrm{~J} / \mathrm{cm}^{2}$. This treatment brought a significant improvement of contractures and permitted a decrease of dose and eventual elimination of CyA. During this time, patient remained under the care of haematologists. In 2010, a subsequent course of UVA1 exposures, at $30 \mathrm{~J} / \mathrm{cm}^{2}, 18$ exposures up to the total dose of $430 \mathrm{~J} / \mathrm{cm}^{2}$ yielded less advantageous effect on lichenoid lesions, which, on the other hand, reacted very well to low systemic doses of glucocorticoids.

Scleromyxedema is a rare, chronic and progressive disease which may involve the skin and other internal organs. Is characterised by a generalised papular and sclerodermoid eruption, the presence of mucin deposition of reticular dermis, fibroblast proliferation and fibrosis with an absence of a thyroid disorder, often accompanied by monoclonal gammapathy. Response to treatment with cyclophosphamide and steroids used to be unsatisfactory [76]. Literature of the subject contains few papers on application of UVB and PUVA in treatment of the disease. In 1984, Farr described 20 patients treated with BB-UVB and PUVA baths and demonstrated better results using PUVA while UVB even exacerbated course of the disease in one case [77]. Subsequently, PUVA photochemotherapy was applied as well as parallel application of PUVA and melphalan or PUVA and systemic steroids, noting general improvement but also a case complicated by appearance of multiple keratoacanthomas and development of SCC [78]. Until now, no cases of scleromyxedema treated with UVA1 were published except of a single case of a mild disease, in which a moderate clinical improvement was observed [79].

Scleredema is another rare condition characterised by induration of the skin and erythema which sometimes may be associated with the history of febrile illness-called scleredema Bushke or diabetes. The literature contains reports on efficacy of PUVA baths, local PUVA and ECP. In 2004, Janiga et al. applied low doses of UVA1 in 2 patients with scleroedema in diabetics and scleroedema Bushke and observed disappearance of lesions [80]. Tuchinda et al. in 2006 irradiated 6 patients (including 5 patients with diabetes mellitus) with low and moderate dose of UVA1. Five patients completed the treatment with a moderate or good results, where one patient suffered from a relapse after 15 months [81]. Eberlein-Konig et al. in 2005 described a single case treated with a moderate UVA1 dose $\left(50 \mathrm{~J} / \mathrm{cm}^{2}\right)$ with clinical improvement, confirmed by HF USG patterns [82].

The syndrome of POEMS (polyneuropathy, organomegaly, endocrinopathy, monoclonal protein, skin changes) is a very rare disease associated with the presence of indurating skin lesions. One severe case was described which was found to be resistant to standard chemotherapy, but showed improvement following 35 exposures to low UVA1 doses [83].

Nephrogenic fibrosing dermopathy (NFD) is a disease of fibrosis of the skin and internal organs that occurre in patients with renal insufficiency. A 47-year-old female patient was described, suffering from for 2 months who was treated with high dose UVA1 dose 12 weeks. A good clinical effect was obtained, confirmed by biopsy of the altered skin before and after exposures as well as of normal skin. Amounts of collagen were estimated by determination of hydroxyproline level as well as expressions of mRNA for procollagen I, collagen III, TGF- $\beta$ and CTGF were compared [84].

\section{Discussion}

It seems that both systemic photochemotherapy, PUVA baths and UVA1 show favourable effects in treatment of some types of morphea. In further studies it will be significant to compare the two methods in their efficacy and safety. Although UVA1 therapy has not been evaluated in systemic sclerosis under setting of randomized clinical trials, small open studies and single case reports indicate that UVA1 therapy might be of benefit in treating skin involvement in patients with systemic sclerosis. Up to date no efficacy of UVA1 with respect to SSc-related internal organ involvement has been reported.

The high, moderate and low doses of UVA1 were found to be effective. Some authors regard moderate doses as the optimum solution while other stress significance of low doses, which is a more accessible treatment. However, it still remains unknown whether the positive effect reflects the applied daily dose, in a standard way subdivided to low doses of UVA1, $<20 \mathrm{~J} / \mathrm{cm}^{2}$, moderate doses of UVA1, 20-90 $\mathrm{J} / \mathrm{cm}^{2}$, high doses of UVA1, $90-130 \mathrm{~J} / \mathrm{cm}^{2}$ or the total dose, also subdivided to low (TD $<300 \mathrm{~J} / \mathrm{cm}^{2}$ ), moderate (TD $300-975 \mathrm{~J} / \mathrm{cm}^{2}$ ) and high (TD $>975 \mathrm{~J} / \mathrm{cm}^{2}$ ) doses.

Obviously, it should not be expected that scleroderma lesions will fully regress leaving a healthy looking skin. At the preliminary phase the therapy aims rather at restricting the inflammatory process, manifested by presence of the liliac ring and at softening of the sclerotic plaques. The frequently noted phenomenon involves manifestation of postinflammatory hyperpigmentation. The sclerotic plaques manifest a tendency for pigmentation more accentuated than that of the normal skin and clinically undetectable foci of the disease may become apparent following a cycle of exposures and the patient should be informed about it [60]. Some authors suggest also that patients with shorter anamnesis and a lighter phototype respond better to the treatment [61].

According to American authors, the first line of treatment for generalized morphea should involve phototherapy, dependent on accessibility (UVA1, BB UVA or possibly NB UVB, dependent on accessibility and other factors). 
This treatment provides a better safety profile, when compared to methotrexate or systemic glucocorticoids [10, 11]. The method of UVA1 is free of side effects, associated with psoralen application, that is required in standard PUVA therapy and has reduced phototoxic effects. Disadvantages include high cost of the equipment and accessibility restricted to specialized centres.

Ultraviolet A1 phototherapy seems to offer a promising approach to treatment of some types of morphea, skin involvement in systemic sclerosis as well as other rare fibrotic dermal diseases. Unfortunately, rational basis for such a treatment is based on descriptions of individual cases or their short series. Therefore, further, multicentre studies are required to more accurately define treatment schedules. Presently, due to the high cost of equipment required for UVA1 phototherapy, such treatment represents a valuable supplementation of standard phototherapy approaches in centres which have at their disposal the respective equipment.

\section{References}

1. Jabłońska S, Majewski S (eds.) (2008): Diseases of the skin and sexually transmitted disorders. Wydawnictwo Lekarskie PZWL, Warszawa 2008.

2. Wolska H (ed.). (2006): Phototherapy in dermatology. Wydawnictwo Czelej, Lublin 2006.

3. Mutzhas MF, Hölzle E, Hofmann C, Plewig G (1981): A new apparatus with high radiation energy between $320-460 \mathrm{~nm}$ : physical description and dermatological applications. J Invest Dermatol 76: 42-47.

4. Krutmann J, Czech W, Diepgen T, et al. (1992): High-dose UVA1 therapy in the treatment of patients with atopic dermatitis. J Am Acad Dermatol 26: 225-230.

5. Darsow U, Wollenberg A, Simon D, et al. (2010): ETFAD/EADV eczema task force 2009 position paper on diagnosis and treatment of atopic dermatitis. J Eur Acad Dermatol Venereol 24: 317-328.

6. Olek-Hrab K, Osmola-Mańkowska A, Silny W, et al. (2011): Use of UVA1 in the treatment of mycosis fungoides - case report. Postep Derm Alergol 2: 158-164.

7. Malinowska K, Sysa-Jędrzejowska A, Woźniacka A. (2011): UVA1 phototherapy in dermatological treatment. Postep Derm Alergol 1: 46-51.

8. Breuckmann F, Gambichler T, Altmeyer P, Kreuter A (2004): UVA/UVA1 phototherapy and PUVA photochemotherapy in connective tissue diseases and related disorders: a research based review. BMC Dermatol 4: 11.

9. Badea I, Taylor M, Rosenberg A, Foldvari M (2009): Pathogenesis and therapeutic approaches for improved topical treatment in localized scleroderma and systemic sclerosis. Rheumatology (Oxford) 48: 213-221.

10. Fett N, Werth VP (2011): Update on morphea. Part I. Epidemiology, clinical presentation, and pathogenesis. J Am Acad Dermatol 64: 217-228.

11. Fett N, Werth VP (2011): Update on morphea. Part II. Outcome measures and treatment. J Am Acad Dermatol 64: 231242 .

12. Akimoto S, Ishikawa O, Yokoyama Y, et al. (1996): Generalized morphea with vascular involvement. A case report and disaccharide analysis of the skin glycosaminoglycans. Acta Derm Venereol 76: 141-143.

13. Kobayasi T, Serup J (1985): Vascular changes in morphea. Acta Derm Venereol 65: 116-120.

14. Hatamochi A, Ono M, Arakawa M, et al. (1992): Analysis of collagen gene expression by cultured fibroblasts in morphoea. Br J Dermatol 126: 216-221.

15. Vierra E, Cunningham BB (1999): Morphea and localized scleroderma in children. Semin Cutan Med Surg 18: 210-225.

16. Chung L, Lin J, Furst DE, Fiorentino D (2006): Systemic and localized scleroderema. Clin Dermatol 24: 374-392.

17. Aberer E, Neumann R, Stanek G (1985): Is localised scleroderma a Borrelia infection? Lancet 2: 278.

18. Colver GB, Rodger A, Mortimer PS, et al. (1989): Post-irradiation morphea. Br J Dermatol 120: 831-835.

19. Kühnl P, Sibrowski W, Kalmar G, et al. (1990): HLA-antigen frequencies in patients with progressive systemic sclerosis and morphea. Beitr Infusionsther 26: 287-289.

20. Di Lorenzo G, Mansueto P, Melluso M, et al. (1997): Morphea after silicone gel breast implantation for cosmetic reasons in an HLA-B8, DR3-positive woman. Int Arch Allergy Immunol 112: 93-95.

21. Szymanek M, Chodorowska G, Kowal M, et al. (2010): Serum soluble Fas levels in patients with systemic sclerosis. Postep Derm Alergol 5: 406-414.

22. Michalska-Jakubus M, Chodorowska G, Krasowska D (2010): Nailfold capillaroscopy. Microscopic assessment of microcirculation abnormalities in systemic sclerosisin systemic sclerosis. Postep Derm Alergol 2: 106-118.

23. Sgonc R, Gruschwitz MS, Dietrich H, et al. (1996): Endothelial cell apoptosis is a primary pathogenic event underlying skin lesions in avian and human scleroderma. J Clin Invest 98: 785-792.

24. Dziankowska-Bartkowiak B, Żebrowska A, WągrowskaDanielewicz M, et al. (2009): Systemic sclerosis and scleroderma circumscripta disturbances of selected serum parameters which are responsible for vascular changes and CD34 expression in involved skin. Przegl Lek 66: 1040-1045.

25. Ihn H, Fujimoto M, Sato S, et al. (1994): Increased levels of circulating intercellular adhesion molecule-1 in patients with localized scleroderma. J Am Acad Dermatol 31: 591-595.

26. Yamane K, Ihn H, Kubo M, et al. (2000): Increased serum levels of solube vascular cell adhesion molecule 1 and E-selectin in patients with localized scleroderma. J Am Acad Dermatol 42: 64-69.

27. Olewicz-Gawlik A, Dańczak-Pazdrowska A, Klama K, et al. (2008): Increased serum levels of solube E-selectin and P-selectin in patients with localized scleroderma. Proceedings of the $17^{\text {th }}$ EADV Congress, Paris, France.

28. Ihn H, Sato S, Fujimoto M, et al. (1994): Demonstration of interleukin- 8 in serum samples of patients with localized scleroderma. Arch Dermatol 130: 1327-1328.

29. Yamamoto T, Matsushita M, Yokozeki H (2006): Role of cytokines in scleroderma: use of animal models. Clin Applied Immunol Rev 6: 1-19.

30. Hunzelmann N, Anders S, Fierlbeck G, et al. (1997): Doubleblind, placebo-controlled study of intralesional interferon gamma for the treatment of localized scleroderma. J Am Acad Dermatol 36: 433-435.

31. Coelho LF, de Oliveira JG, Kroon EG (2008): Interferons and scleroderma - a new clue to understanding the pathogenesis of scleroderma? Immunol Lett 118: 110-115. 
32. Vuorio T, Mäkelä JK, Kähäri VM, Vuorio E (1987): Coordinated regulation of type I and type III collagen production and mRNA levels of pro alpha 1(I) and pro alpha 2(I) collagen in cultured morphea fibroblasts. Arch Dermatol Res 279: 154-160.

33. Kähäri VM, Sandberg M, Kalimo H, et al. (1988): Identification of fibroblast responsible for increased collagen production in localized scleroderma by in situ hybridization. J Invest Drematol 90: 664-670.

34. Dziankowska-Bartkowiak B, Waszczykowska E, Żebrowska A (2004): The role of metalloproteinases and their inhibitors in the patomechanisms of skin diseases. Alergia Astma Immunologia 9: 71-79.

35. Tomimura S, Ogawa F, Iwata Y, et al. (2008): Autoantibodies against matrix metaloproteinase-1 in patients with localized scleroderma. J Dermatol Sci 52: 47-54.

36. Kerscher M, Volkenandt M, Meurer M, et al. (1994): Treatment of localised scleroderma with PUVA bath photochemotherapy. Lancet 343: 1233.

37. Kerscher M, Dirschka T, Volkenandt M (1995): Treatment of localised scleroderma by UVA1 phototherapy. Lancet 346 : 1166.

38. Kerscher M, Volkenandt M, Gruss C, et al. (1998): Low-dose UVA1 phototherapy for treatment of localised scleroderma. J Am Acad Dermatol 38: 21-26.

39. El-Mofty M, Zaher H, Bosseila M, et al. (2000): Low-dose broad-band UVA in morphea using a new method for evaluation. Photodermatol Photoimmunol Photomed 16: 43-49.

40. El-Mofty M, Mostafa W, El-Darouty M, et al. (2004): Different low doses of broad-band UVA in the treatment of morphea and systemic sclerosis. Photodermatol Photoimmunol Photomed 20: 148-156.

41. Stege H, Berneburg M, Humke S, et al. (1997): High-dose UVA1 radiation therapy for localised scleroderma. J Am Acad Dermatol 36: 938-944.

42. Kreuter A, Hyun J, Stücker M, et al. (2006): A randomized controlled study of low dose UVA1, medium dose UVA1 and NB UVB phototherapy in the treatment of localized scleroderma. J Am Acad Dermatol 54: 440-447.

43. Camacho NR, Sánchez JE, Martin RF, et al. (2001): Mediumdose UVA1 phototherapy in localized scleroderma and its effect in CD34-positive dendritic cells. J Am Acad Dermatol 45: 697-699.

44. de Rie MA, Enomoto DN, de Vries HJ, Bos JD (2003): Evaluation of medium-dose UVA1 phototherapy in localized scleroderma with the cutometer and fast Fourier transform method. Dermatology 207: 298-301.

45. Andres C, Kollmar A, Mempel M, et al. (2010): Successful ultraviolet A1 phototherapy in the treatment of localized scleroderma: a retrospective and prospective study. J Dermatol 162: 445-447.

46. Pereira N, Santiago H, Oliveira A, et al. (2011): Low-dose UVA1 phototherapy for scleroderma. What benefit can we expect? J Eur Acad Dermatol Venerol 3: 1-8.

47. Gruss C, Stücker M, Kobyletzki G, et al. (1997): Low dose UVA1 phototherapy in disabling pansclerotic morphoea of childhood. Br J Dermatol 136: 293-294.

48. York NR, Jacobe HT (2010): UVA1 phototherapy: a review of mechanism and therapeutic application. Int J Dermatol 49: 623-630.

49. Silny W, Osmola-Mankowska A, Czarnecka-Operacz M, et al. (2009): Eosinophilic fascitis: a case report of two cases treated with ultraviolet A1 phototherapy. Photoderm Photoimmunol Photomed 25: 325-327.
50. Morita A, Kobayashi K, Isomura I, et al. (2000): Ultraviolet A-1 phototherapy for systemic sclerosis. J Am Acad Dermatol 43: 670-674.

51. von Kobyletzki G, Uhle A, Pieck C, et al. (2000): Acrosclerosis in patients with systemic sclerosis responds to low-dose UVA1 phototherapy. Arch Dermatol 136: 275-276.

52. Kreuter A, Breuckmann F, Uhle A, et al. (2004): Low-dose of UVA1 phototherapy in systemic sclerosis: effects on acrosclerosis. J Am Acad Dermatol 50: 740-747.

53. Tewari A, Garibaldinos T, Lai-Cheong J, et al. (2011): Successful treatment of microstomia with UVA1 phototherapy in systemic sclerosis. Photodermatol Photoimmunol Photomed 27: 113-114.

54. Krutmann J, Morita A, Elmets CA (2009): Mechanisms of photo(chemo)therapy. In: Krutmann J, Honigsmann H, Elmets CA (eds.). Dermatological Phototherapy and photodiagnostic methods. $2^{\text {nd }}$ ed. Springer, Berlin-Heidelberg; 63-78.

55. Bernerd F, Asselineau D (1998): UVA exposure of human skin reconstructed in vitro induces apoptosis of dermal fibroblasts: subsequent connective tissue repair and implications in photoaging. Cell Death Differ 5: 792-802.

56. Petersen MJ, Hansen C, Craig S (1992): Ultraviolet A irradiation stimulates collagenase production in cultured human fibroblasts. J Invest Dermatol 99: 440-442.

57. Johnston KJ, Oikarinen AI, Lowe NJ, et al. (1984): Ultraviolet radiation-induced connective tissue changes in the skin of hairless mice. J Invest Dermatol 82: 587-590.

58. El-Mofty M, Mostafa W, Esmat S, et al. (2004): Suggested mechanisms of action of UVA phototherapy in morphea: a molecular study. Photodermatol Photoimmunol Photomed 20: 93-100.

59. Breuckmann F, Stuecker M, Altmeyer P, Kreuter A (2004): Modulation of endothelial dysfunction and apoptosis: UVA1mediated skin improvement in systemic sclerosis. Arch Dermatol Res 296: 235-239.

60. Brenner M, Herzinger T, Berking C, et al. (2005): Phototherapy and photochemotherapy of sclerosing skin diseases. Photodermatol Photoimmunol Photomed 21: 157-165.

61. Kreuter A, Gambichler T (2008): UV-A1 phototherapy for sclerotic skin diseases: implications for optimizing patient selection and management. Arch Dermatol 144: 912-916.

62. Kreuter A, Jansen T, Stücker M, et al. (2001): Low-dose ultraviolet-A1 phototherapy for lichen sclerosus. Clin Exp Dermatol 26: 30-32.

63. Kreuter A, Gambichler T, Avermaete A, et al. (2002): Lowdose ultraviolet A1 phototherapy for extragenital lichen sclerosus: results of a preliminary study. J Am Acad Dermatol 46: 251-255.

64. Beattie PE, Dawe RS, Ferguson J, Ibbotson SH (2006): UVA1 phototherapy for genital lichen sclerosus. Clin Exp Dermatol 31: 343-347.

65. Gilliam AC (2004): Update on graft versus host disease. J Invest Dermatol 123: 251-257.

66. Volc-Platzer B (2009): Photo(chemo)therapy of Graft-versusHost Disease. In: Krutmann J, Honigsmann H, Elmets CA (eds.). Dermatological Phototherapy and photodiagnostic methods. 2nd ed. Springer Berlin-Heidelberg; 185-204.

67. Grundmann-Kollmann M, Behrens S, Gruss C, et al. (2000): Chronic sclerodermic graft-versus-host disease refractory to immunosuppressive treatment responds to UVA1 phototherapy. J Am Acad Dermatol 42: 134-136.

68. Ständer H, Schiller M, Schwarz T (2002): UVA1 therapy for sclerodermic graft-versus-host disease of the skin. J Am Acad Dermatol 46: 799-800. 
69. Calzavara Pinton P, Porta F, Izzi T, et al. (2003): Prospects for ultraviolet A1 phototherapy as a treatment for chronic cutaneous graft-versus-host disease. Haematologica 88: 1169-1175.

70. Ziemer M, Thiele JJ, Gruhn B, Elsner P (2004): Chronic cutaneous graft-versus-host disease in two children responds to UVA1 therapy: improvement of skin lesions, joint mobility, and quality of life. J Am Acad Dermatol 51: 318-319.

71. Wetzig T, Sticherling M, Simon JC, et al. (2005): Medium dose long-wavelength ultraviolet A (UVA1) phototherapy for treaetment of acute and chronic graft-versus-host disease of the skin. Bone Marrow Transplant 35: 515-519.

72. Tuchinda C, Kerr HA, Taylor CR, et al. (2006): UVA1 phototherapy for cutaneous diseases: an experience of 92 cases in the United States. Photodermatol Photoimmunol Photomed 22: 247-253.

73. Rombold S, Lobisch K, Katzer K, et al. (2008): Efficacy of UVA1 phototherapy in 230 patients with various skin diseases. Photodermatol Photoimmunol Photomed 24: 19-23.

74. Gottlöber P, Leiter U, Friedrich W, et al. (2003): Chronic cutaneous sclerodermoid graft-versus-host disease: evaluation by 20-MHz sonography. J Eur Acad Dermatol Venereol 17: 402407.

75. Calzavara-Pinton P, Monari P, Manganoni AM, et al. (2010): Merkel cell carcinoma arising in immunosuppressed patients treated with high-dose ultraviolet A1 (320-400 nm) phototherapy: a report of two cases. Photodermatol Photoimmunol Photomed 26: 263-265.

76. Maciejewska-Radomska A, Sokołowska-Wojdyło M, Wilkowska A, et al. (2011): Scleromyxoedema in a 70-year-old woman - case report and review of the literature. Postep Derm Alergol 1: 56-59.

77. Farr PM, Ive FA (1984): PUVA treatment of scleromyxoedema. Br J Dermatol 110: 347-350.

78. Adachi Y, Iba S, Horio T (2000): Successful treatment of lichen myxoedematosus with PUVA photochemotherapy. Photodermatol Photoimmunol Photomed 16: 229-231.

79. Silny W, Osmola-Mańkowska A, Czarnecka-Operacz M, Szewczyk A (2010): Narrow band UVA1 phototherapy in dermatological treatment - first Polish experiences. Postep Derm Alergol 1: 1-10.

80. Janiga JJ, Ward DH, Lim HW (2004): UVA-1 as a treatment for scleredema. Photodermatol Photoimmunol Photomed 20: 210-211.

81. Tuchinda C, Kerr HA, Taylor CR, et al. (2006): UVA1 phototherapy for cutaneous diseases: an experience of 92 cases in the United States. Photodermatol Photoimmunol Photomed 22: $247-253$.

82. Eberlein-König B, Vogel M, Katzer K, et al. (2005): Successful UVA1 phototherapy in a patient with scleredema adultorum. J Eur Acad Dermatol Venereol 19: 203-204.

83. Schaller M, Romiti R, Wollenberg A, et al. (2001): Improvement of cutaneous manifestations in POEMS syndrome after UVA1 phototherapy. J Am Acad Dermatol 45: 969-970.

84. Kafi R, Fisher GJ, Quan T, et al. (2004): UV-A1 improves nephrogenic fibrosing dermopathy. Arch Dermatol 140: 13221324. 